\title{
Application of DNA chip techniques for Yq microdeletion analysis in infertile males
}

\author{
Suman Lee ${ }^{1 *}$, Hyun Suk Joo ${ }^{2 *}$ \\ Sook-Hwan Lee ${ }^{1}$, Jung Eun Park ${ }^{2}$ \\ Jong Man $\mathrm{Kim}^{2}$, Jae Hoon $\mathrm{Hwang}^{2}$ \\ Key Seung $\mathrm{Cho}^{2}$ and Seung Yong Hwang ${ }^{2,3}$ \\ ${ }^{1}$ Genome Research Center for \\ Reproductive Medicine and Infertility \\ Infertility Medical Center, CHA General Hospital \\ College of Medicine, Pochon CHA University \\ Seoul 135-913, Korea \\ ${ }^{2}$ Department of Biochemistry \& MicroBiochip Center \\ Hanyang University \& GenoCheck Co. Ltd. \\ Ansan, Gyeonggi-do 426-791, Korea \\ ${ }^{3}$ Corresponding author: Tel, 82-31-400-5516; \\ Fax, 82-31-502-5518; E-mail, syhwang@hanyang.ac.kr \\ *These authors contributed equally to this work.
}

Accepted 7 April 2004

Abbreviations: AZF, azoospermia factors; DNA, Deoxyribonucleic acid; ICSI, intracytoplasmic sperm injection; IVF, in vitro fertilization; OAT, oligo atheno teratozoospermia; PCR, polymerase chain reaction; SCO, sertoli-cell-only; SDS, sodium dodecyl sulfate; SSC, saline sodium citrate; STS, sequence tagged site; UV, ultraviolet

\footnotetext{
Abstract

Our aim was to apply DNA chip technology as a diagnostic tool in infertility research and clinics. Six loci, including a sex-determining region on the $Y$ chromosome and five sequence-tagged sites in azoospermia-factor regions were investigated in infertile male patients. Our method produced a sensitive signal, which showed the presence or absence of the STS regions on the $Y$ chromosome. The results from 93 patients with nonobstructive azoospermia, oligoathenoteratozoospermia, or oligozoospermia were identical when analyzed with either the DNA chip technique or conventional PCR-gel electrophoresis. We have demonstrated its application in the molecular diagnosis of male infertility. This system provides an economic and high-throughput method for detecting the deletion of genomic DNA sequences of large groups of infertile patients, and a completely new approach to male infertility screening.
}

The application of DNA chip technology to identify Yq deletions can also facilitate our understanding of male infertility.

Keywords: DNA chip; male infertility; microdeletion; molecular diagnosis; STS

\section{Introduction}

Y-chromosomal deletions represent the most frequent genetic alterations in infertile men (Chandley and Cooke, 1994). The frequency of deletions on the long arm of the $\mathrm{Y}$ chromosome $(\mathrm{Yq})$ in infertile male patients varies from $1 \%$ to $51 \%$ depending on patient selection criteria (van der Ven et al., 1997; Foresta et al., 1998). Microdeletions on Yq are closely associated with severe infertility, with some correlation between genotype and phenotype (Foresta et al., 2001; Kamp et al., 2001; Dohle et al., 2002). Because the use of intracytoplasmic sperm injection (ICSI) and other related techniques has explosively increased the pregnancy rate of male infertility patients in in vitro fertilization (IVF) clinics, it is important to screen for possible genetic defects that can be passed to the next generation.

Screening for microdeletions in azoospermia factors (AZF) a, b, or $c$ is routinely performed in major andrology and infertility centers. Deletions in the AZFc region on $\mathrm{Yq}$ are the most common cause of spermatogenic failure (Dohle et al., 2002; Sawai et al., 2002). AZFa deletions occur with high frequency in the Sertoli-cell-only (SCO) patient group (Kamp et al., 2001). A genetic diagnostic method for Y-chromosome microdeletions associated with male infertility has been developed on the basis of conventional polymerase chain reaction (PCR) and standard gel electrophoresis methods (Maurer and Simoni, 2000). A multiple PCR method has been reported (Bor et al., 2001), and a commercial PCR primer-mix kit has also been developed. However, analysis of multiple PCR products on a gel based on its molecular size and intensity is sometimes quite complicated and dependent on the experience of researcher (Figure 1).

DNA chip technology is used increasingly to diagnose and identify genes related to human disease. It has become a widely applied tool for genetic diagnosis (Wallace, 1997; Hwang and Lim, 2000; Fortina et al., 2002; Kim et al., 2003). We have 
developed a DNA chip technique to screen for $\mathrm{Yq}$ microdeletions in infertile male patients. This newly developed method can allow high-throughput screening of large groups of infertile patients in infertility clinics, compared to conventional PCR-gel electrophoresis method (Figure 1).

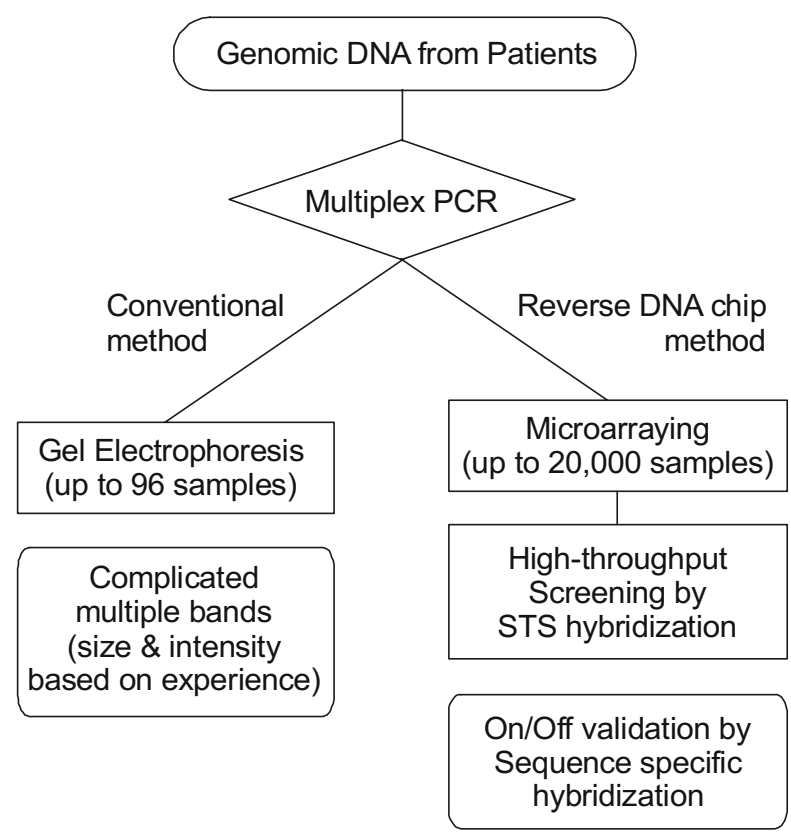

Figure 1. Comparison between conventional and reverse DNA chip methods for $\mathrm{Yq}$ microdeletion analysis. Strength and weakness points are represented on the bottom of each method.

\section{Materials and Methods}

\section{Patients and controls}

The Institutional Review Board of CHA General Hospital approved this genetic study in June 1998. From July 1998 to December 2000, 93 non-obstructive infertile men and 46 healthy fertile subjects consented to the use of their blood. Seventy-three non-obstructive infertile patients with azoospermia, 18 with severe oligoathenoteratozoospermia (OAT), and two with oligozoospermia were included in this study at the CHA General Hospital. We did all cytogenetic and $\mathrm{Yq}$ microdeletion analysis of these patients, and the general clinical implication on this group was reported previously (Lee et al., 2003). Forty-six healthy, fertile Korean men were used as controls. Only normal subjects with at least one child and no history of assisted reproductive technology were included in the control group. One healthy fertile female was included as a negative control with two buffer only samples. Each PCR product identified by gel electrophoresis was used as positive control. All samples were collected with informed consent.

\section{Polymerase Chain Reaction (PCR)}

Genomic DNA was obtained from peripheral blood leukocytes. The PCR reaction was carried out in a total volume of $50 \mu \mathrm{l}$ containing $100 \mathrm{ng}$ extracted DNA, $200 \mathrm{M}$ dNTP, $10 \mathrm{mM}$ Tris-Cl (pH 8.3), $1.5 \mathrm{mM}$ $\mathrm{MgCl}_{2}$, and $50 \mathrm{mM} \mathrm{KCl}$. Two units of Taq DNA polymerase was added under hot-start conditions and amplification was carried out in a 2400 Thermocycler (Perkin Elmer, CT) for 30 cycles of $94^{\circ} \mathrm{C}$ for $30 \mathrm{~s}$, $58^{\circ} \mathrm{C}$ for $30 \mathrm{~s}, 72^{\circ} \mathrm{C}$ for $30 \mathrm{~s}$, with a $7 \mathrm{~min}$ final ex-

Table 1. Sequences of primer set.

\begin{tabular}{|c|c|c|c|}
\hline STS & Size $(b p)$ & Primer & Sequence 5'-3' \\
\hline SRY & 204 & $\begin{array}{l}\text { Upstream } \\
\text { Downstream }\end{array}$ & $\begin{array}{l}\text { CATGAACGCATTCATCGTGTG } \\
\text { GGTCGATACTTATAATTCGGG }\end{array}$ \\
\hline sY158 & 231 & $\begin{array}{l}\text { Upstream } \\
\text { Downstream }\end{array}$ & $\begin{array}{l}\text { CTCAGAAGTCCTCCTAATAGTTCC } \\
\text { ACAGTGGTTTGTAGCGGGTA }\end{array}$ \\
\hline sY254 & 350 & $\begin{array}{l}\text { Upstream } \\
\text { Downstream }\end{array}$ & $\begin{array}{l}\text { GGGTGTTACCAGAAGGCAAA } \\
\text { GACCGTATCTACCAAAGCAGCA }\end{array}$ \\
\hline sY134 & 301 & $\begin{array}{l}\text { Upstream } \\
\text { Downstream }\end{array}$ & $\begin{array}{l}\text { TGTCTGCCTCACCATAAAAC } \\
\text { CAACCACTGCCAAAACTTTC }\end{array}$ \\
\hline SPGY1 & 460 & $\begin{array}{l}\text { Upstream } \\
\text { Downstream }\end{array}$ & $\begin{array}{l}\text { TTCACATACAGCCATTAAGTTTAGC } \\
\text { ACAATTTGATAGTCTGAACACAAGC }\end{array}$ \\
\hline sY127 & 300 & $\begin{array}{l}\text { Upstream } \\
\text { Downstream }\end{array}$ & $\begin{array}{l}\text { TAGAGGCTAGGCTCACAAAC } \\
\text { AAGCTGCAGGCAGTAATAAG }\end{array}$ \\
\hline
\end{tabular}


tension step at $72^{\circ} \mathrm{C}$. The oligonucleotide sequences of the 12 primers used to amplify SRY and five sequence-tagged sites (sY127, sY134, SPGY1, sY254, sY158) are given in Table 1. Routine PCR amplification of genomic DNA was performed. Based on previous microdeletion study on this selected group, we only used these five STS markers for this DNA chip experiment (Lee et al., 2003).

\section{DNA chip analysis}

\section{Preparation of probes}

Using the genomic DNA of 46 normal fertile subjects and 93 infertile patients, multiplex PCR was performed to amplify six markers on the human $Y$ chromosome. Thirty cycles of PCR were performed as follows: $30 \mathrm{~s}$ at $94^{\circ} \mathrm{C}, 30 \mathrm{~s}$ at $60^{\circ} \mathrm{C}$, and $30 \mathrm{~s}$ at $72^{\circ} \mathrm{C}$. Products were ethanol precipitated, dried, and dissolved in $10 \mu \mathrm{l}$ of $3 \times$ saline sodium citrate (SSC) for arraying.

\section{Arraying procedure and processing}

PCR products were arrayed from 96-well microtiter plates onto Superamine glass slides (Telechem, CA) using a high-speed microarrayer (Cartesian Technology, MI). A mixture of the six STS markers was also spotted as a positive control. The printed chips were rehydrated for $1 \mathrm{~min}$ in a humid chamber, then snap-dried for $3 \mathrm{~s}$ on a hot-plate $\left(100^{\circ} \mathrm{C}\right)$. The DNA was then UV-crosslinked to the surfaces by subjecting the slides to $60 \mathrm{~mJ}$ of energy. The rest of the glass surface was blocked by $15 \mathrm{~min}$ incubation in a solution of $1 \mathrm{M}$ succinic anhydride dissolved in $45 \mathrm{ml}$ 1-methyl-2-pyrrolidinone (Merck, NJ) and $5 \mu \mathrm{l}, 1 \mathrm{M}$ sodium borate (boric acid, $\mathrm{pH} 8.0$ ).

\section{Target preparation}

To prepare the target, each STS marker was amplified by PCR using the same primer sets and conditions described for probe preparation. After ethanol precipitation, the PCR products were labeled individually with Cy3-dCTP using the Prime-It II Random Primer Labeling kit (Stratagene, CA). The fluorescent DNA samples were then diluted to $500 \mu \mathrm{l}$ with $T E$, and concentrated to $10 \mu$ using a Microcon-30 column (Millipore, MA).

\section{Hybridization}

Purified labeled target was resuspended in $11 \mu \mathrm{l} 3.5$ xSSC containing $0.3 \%$ sodium dodecyl sulfate (SDS). The sample was then heated for $2 \mathrm{~min}$ in boiling water, cooled rapidly to room temperature, and applied to the chip. The chip was placed in a sealed humidified hybridization chamber. Samples were hybridized for $5 \mathrm{~h}$ in a water bath at $65^{\circ} \mathrm{C}$, after the chips were washed immediately in $2 \times S S C$ containing $0.2 \%$ SDS for $6 \mathrm{~min}$, then twice again in $0.05 \times \mathrm{SSC}$.

\section{Scanning (analysis)}

Arrays were scanned on an Axon 4000B laser scanner (Axon, CA). The images were analyzed using the GenePix program (Axon, CA).

\section{Results}

Ninety-three infertile patients and forty-six normal subjects were selected as described in materials and methods. Genomic DNA from healthy controls and from infertile patients was first screened individually by PCR analysis for deletions in six loci on the $Y$

A

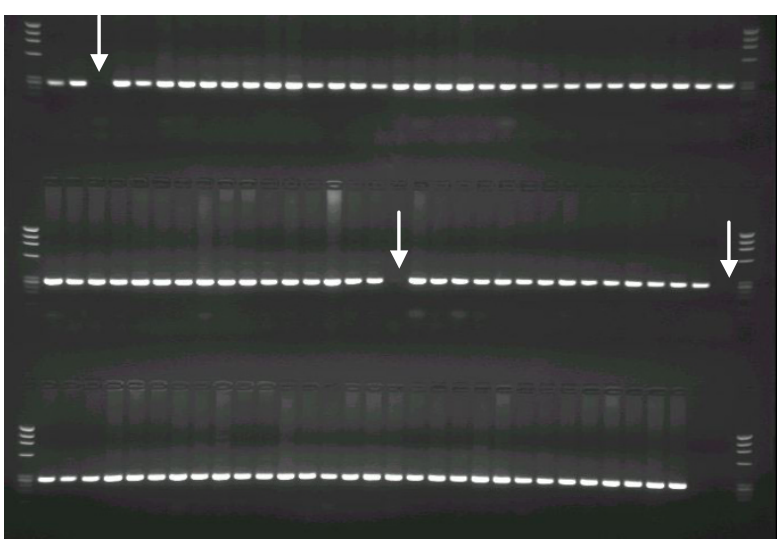

B

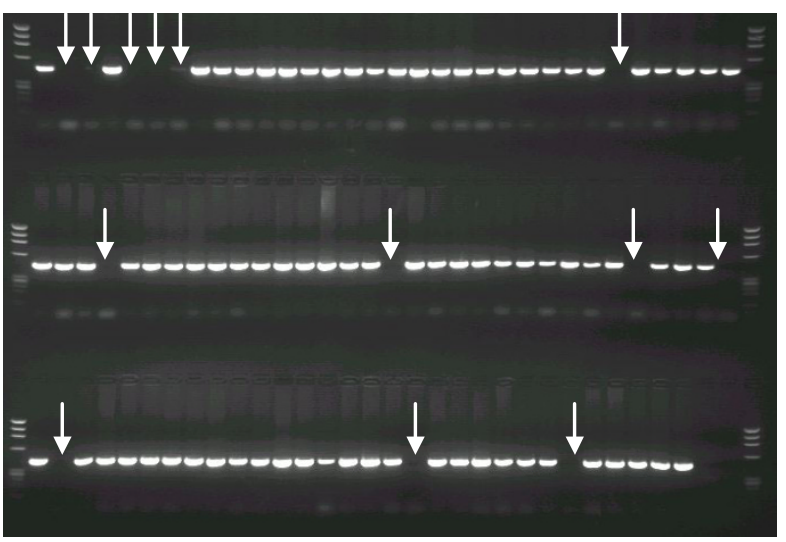

Figure 2. Analysis of PCR products amplified by using $s Y 127$ and sY254 primer sets. Infertility patients $(93 \mathrm{men})$ and normal men (46 men) were amplified by sY127 (A) and sY254 (B) primer sets. Patients with deletion were marked by arrow. 
chromosome (SRY, sY127, sY134, SPGY1, sY254, sY158). From the PCR analysis, 3 (from sY127), 3 (sY134), 13 (SPGY1), 13 (sY254), and 12 (sY158) patients were screened to have deletion, and the PCR products amplified by sY127 and sY254 primer sets were shown in Figure 2.

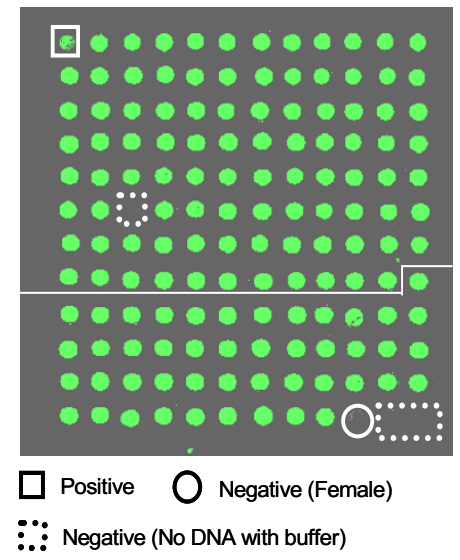

Figure 3. Spotting designs for reverse DNA chip assay. Infertility patients $(93$ men) and normal men (46 men) were spotted on the chip, and divided by the line. Positive control (1 STS mixture marked by the bold box), and negative controls (one female marked by the circle and three no DNA with buffer marked by the dotted box) were shown.
To prepare probes for DNA chip, multiplex PCR products (from a total of 143 sources: 93 patients, 46 normal subjects, and four negative controls) amplified by mixed primer set (SRY, sY127, sY134, SPGY1, sY254, sY158) were precipitated, and then spotted onto glass slides in the order shown in Figure 3 . Therefore, spots on the chip represent only amplified STS regions without microdeletion.

The results of the reverse DNA chip technique are shown in Figure 4, and the presence of each STS marker is visualized in green (Сy3). Half value of the average intensity of 46 normal subjects was used as a cut off intensity value for deletion (Figure 5). The results corresponded completely to the PCR data generated with the genomic DNA from patients with deletions and normal control subjects. As we expected, spots of 46 normal controls were hybridized with all of the 6 STS markers and low background signal was only detected on the spots of deleted patients (Figure 4). Therefore, we do not find any potential error during these reverse DNA chip experiments including 139 multiplex PCR products for probe preparation and hybridizations with 6 different STS markers.

The value for SRY for the negative control (woman) was 1657, which is 6.20 -fold lower than the positive average (10268.66 \pm 5096.87$)$. The value for sY134 from healthy subjects was $5218 \pm 1904.79$,
A

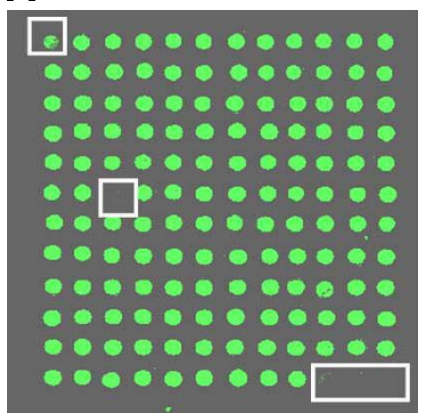

D

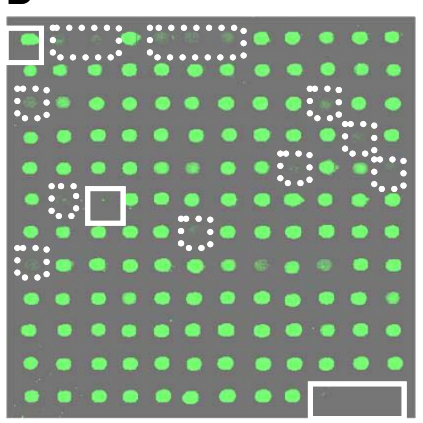

B

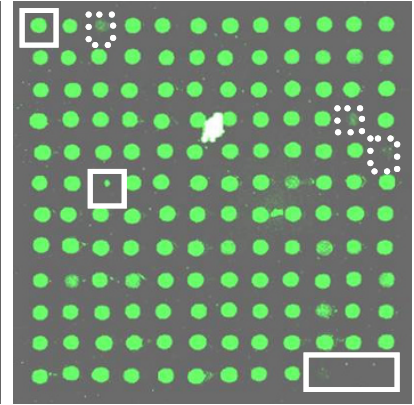

E

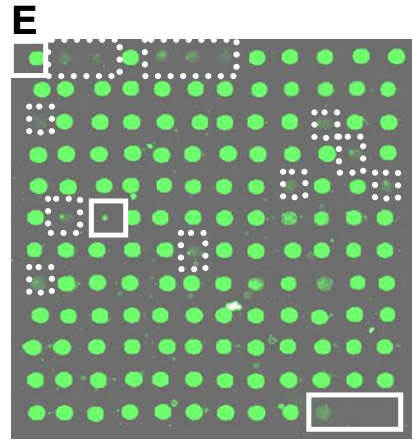

C

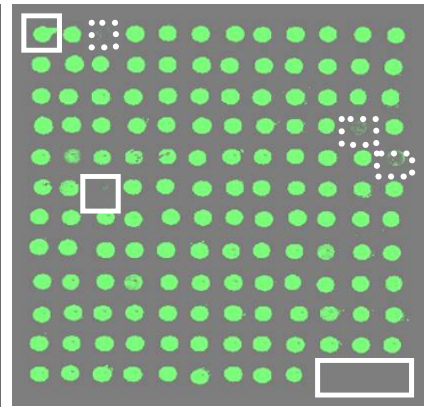

$\mathbf{F}$

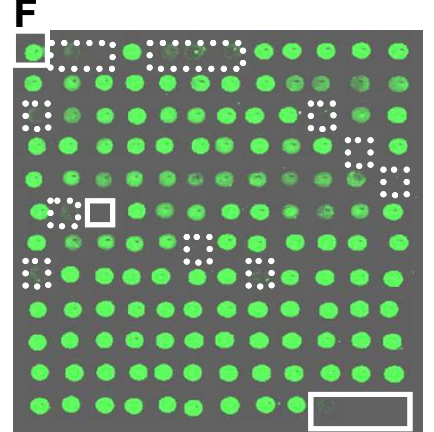

Figure 4. Scanned images of DNA chip from patients were shown. A: SRY, B: sY127, C: sY134, D: SPGY1, E: sY254, F: sY158. The order of spots was same as Figure 3. Deleted patients (dotted box), and positive and negative controls (bold box) were shown. 


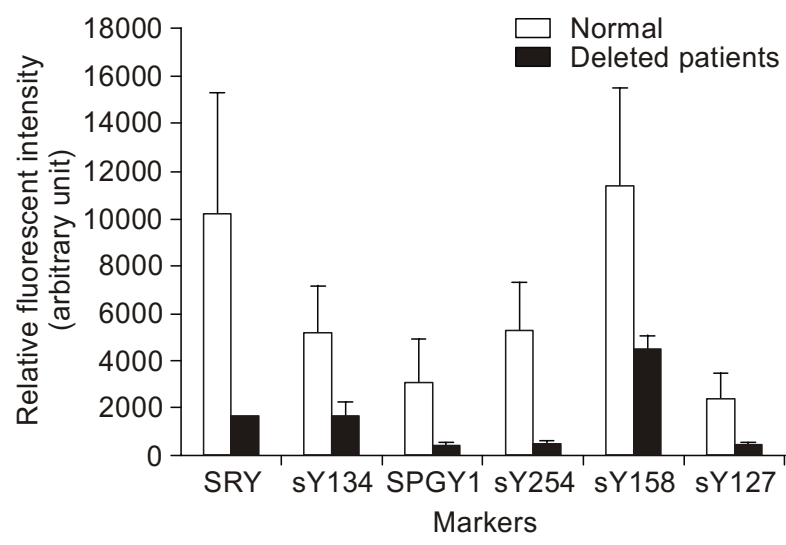

Figure 5. Sensitivities of DNA chip of $Y$ chromosome microdeletions. The average of each spot from normal ( $\square$ ) and the site specific deleted patients (ם) was shown.

3.06-fold higher the average negative value (1707.8 $\pm 599.03) ;$ the value for SPGY1 was $3113.95 \pm$ $1836.97,7.09$-fold higher than the average negative value $(439 \pm 75.54)$; the value for sY254 was 5300 \pm 2036.94 , 9.79-fold higher (the highest value) than the average negative value $(541.21 \pm 65.75)$; the value for sY158 was $11347.46 \pm 4188.33,2.52$-fold higher than the average negative value (4506.85 \pm 523.98); and the value for sY127 was $2400 \pm$ $1001.259,5.65$-fold higher than the average negative value $(425 \pm 96.46)$. These results are shown in Figure 5. Therefore, this reverse DNA chip experiment is an accurate and verifiable method for microdeletion analysis in infertile males.

\section{Discussion}

We took samples from normal controls and infertile patients. Multiple STS-based PCR products from each patient were transferred to glass slides. The negative control (female) value for SRY was 1657, which is 6.20 -fold lower than the average positive value. The chip results correlate with the PCR results insofar as no PCR-negative specimens were identified as positive by reverse DNA chip analysis, and no PCRpositive samples were identified as negative by reverse DNA chip analysis. Therefore, as expected, this method was equally sensitive to analysis using PCR and gel electrophoresis for the samples tested, and none of the observed PCR products from patient DNA produced false-positive results. Also, reverse DNA chip analysis might give more accurate results than gel electrophoresis analysis because of their sequence specific hybridization. Analysis of conventional multiple PCR products on a gel based on its molecular size is quite complicated and troublesome in many infertility centers (Figure 1).

DNA chip technology could provide a useful tool for the molecular diagnosis of male infertility in clinical laboratories, especially for high-throughput analyses. We have demonstrated the successful use of a system of fluorescently-labeled targets that greatly improves the sensitivity and specificity of detection. The application of DNA chip technology to the identification of $\mathrm{Y}$-chromosome deletions will also facilitate greater understanding of male infertility.

These experiments demonstrate the potential for DNA chips in identifying $Y$-chromosome deletions. Although it is not currently cost-effective to array of every STS marker, experimental results may lead to the identification of a set of genetic markers that can be used to generate a diagnostic array for use in the clinical setting in the near future. Furthermore, the time and cost of this technique could be greatly improved by labeling STS respectively with 5 or 6 different fluorescent dyes for single hybridization. Recent DNA chip scanner systems offer 5 or 6 different channels that can be scanned simultaneously. Also, we can diagnose on a massive scale, with a spot number of up to 20,000 on a chip. This procedure could be particularly useful in screening for specific marker genes on the $Y$ chromosome.

\section{Acknowledgement}

This study was supported by Genome Research Center for Reproductive Medicine and Infertility (01-PJ10-PG6-01GN13-0002) from the Ministry of Health and Welfare, Korea.

\section{References}

Bor P, Hindkjaer J, Ingerslev HJ, Kolvraa S. Multiplex PCR for screening of microdeletions on the $\mathrm{Y}$ chromosome. J Assist Reprod Genet 2001;18:291-8

Chandley AC, Cooke HJ. Human male fertility-Y-linked genes and spermatogenesis. Hum Mol Genet 1994;3:1449-52

Dohle GR, Halley DJ, Van Hemel JO, van den Ouwel AM, Pieters MH, Weber RF, Govaerts LC. Genetic risk factors in infertile men with severe oligozoospermia and azoo spermia. Hum Reprod 2002;17:13-6

Foresta C, Ferlin A, Garolla A, Moro E, Pistorello M, Barbaux $S$, Rossato $M$. High frequency of well-defined Y-chromosome deletions in idiopathic Sertoli cell-only syndrome. Hum Reprod 1998;13:302-7

Foresta C, Moro E, Ferlin A. Y chromosome microdeletions and alterations of spermatogenesis. Endocr Rev 2001;22: 226-39

Fortina P, Surrey S, Kricka LJ. Molecular diagnostics: hurdles for clinical implementation. Trends Mol Med 2002;8:264-6 
Hwang SY, Lim GB. DNA chip technologies. Biotech Biopro Eng 2000;5:159-63

Kamp C, Huellen K, Fernandes S, Sousa M, Schlegel PN, Mielnik A, Kleiman S, Yavetz H, Krause W, Kupker W. High deletion frequency of the complete AZFa sequence in men with Sertoli-cell-only syndrome. Mol Hum Reprod 2001;7:98794

Kim JR, Lee SR, Chung HJ, Kim SY, Baek SW, Kim JH, Kim YS. Identification of amyloid $\beta$-peptide responsive genes by cDNA chip technology: Involvement of RTP801 in amyloid $\beta$-peptide toxicity. Exp Mol Med 2003;35:403-11

Lee S, Kim NK, Kim HJ, Lee SH, Jeong HJ, Cha KY. Genetic analysis of three polymorphic sites of LH $\beta$-subunit gene in infertile Korean men with nonobstructive azoo- spermia. Fertil Steril 2003;79:517-21

Maurer B, Simoni M. Y chromosome microdeletion screening in infertile men. J Endocrinol Invest 2000;23:664-70

Sawai H, Komori S, Koyama K. Molecular analysis of the $Y$ chromosome AZFc region in Japanese infertile males with spermatogenic defects. J Reprod Immunol 2002;53:37-44

van der Ven K, Montag M, Peschka B, Leygraaf J, Schwanitz G, Haidl G, Krebs D, van der Ven H. Combined cytogenetic and $Y$ chromosome microdeletion screening in males undergoing intracytoplasmic sperm injection. Mol Hum Reprod 1997:3:699-704

Wallace RW. DNA on a chip: serving up the genome for diagnostics and research. Mol Med Today 1997;3:384-9 